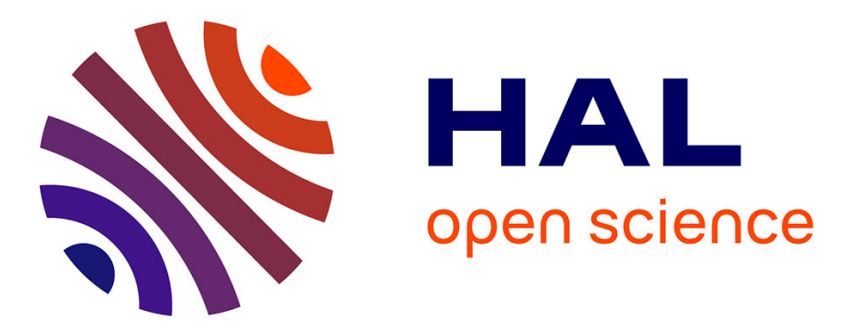

\title{
Impact of Magnetic Field Strength on Resolution and Sensitivity of Proton Resonances in Biological Solids
}

Kai Xue, Riddhiman Sarkar, Daniela Lalli, Benita Koch, Guido Pintacuda, Zdenek Tosner, Bernd Reif

\section{- To cite this version:}

Kai Xue, Riddhiman Sarkar, Daniela Lalli, Benita Koch, Guido Pintacuda, et al.. Impact of Magnetic Field Strength on Resolution and Sensitivity of Proton Resonances in Biological Solids. Journal of Physical Chemistry C, 2020, 124 (41), pp.22631-22637. 10.1021/acs.jpcc.0c05407 . hal-03457084

\author{
HAL Id: hal-03457084 \\ https://hal.science/hal-03457084
}

Submitted on 30 Nov 2021

HAL is a multi-disciplinary open access archive for the deposit and dissemination of scientific research documents, whether they are published or not. The documents may come from teaching and research institutions in France or abroad, or from public or private research centers.
L'archive ouverte pluridisciplinaire HAL, est destinée au dépôt et à la diffusion de documents scientifiques de niveau recherche, publiés ou non, émanant des établissements d'enseignement et de recherche français ou étrangers, des laboratoires publics ou privés. 


\title{
Impact of Magnetic Field Strength on Resolution and Sensitivity of Proton Resonances in Biological Solids
}

\author{
Kai Xue, Riddhiman Sarkar*, Daniela Lalli, Benita Koch, \\ Guido Pintacuda, Zdenek Tosner, and Bernd Reif* \\ J. Phys. Chem. C 2020, 124, 41, 22631-22637 \\ Publication Date:September 30, 2020 \\ https://doi.org/10.1021/acs.jpcc.0c05407
}

\section{Abstract}
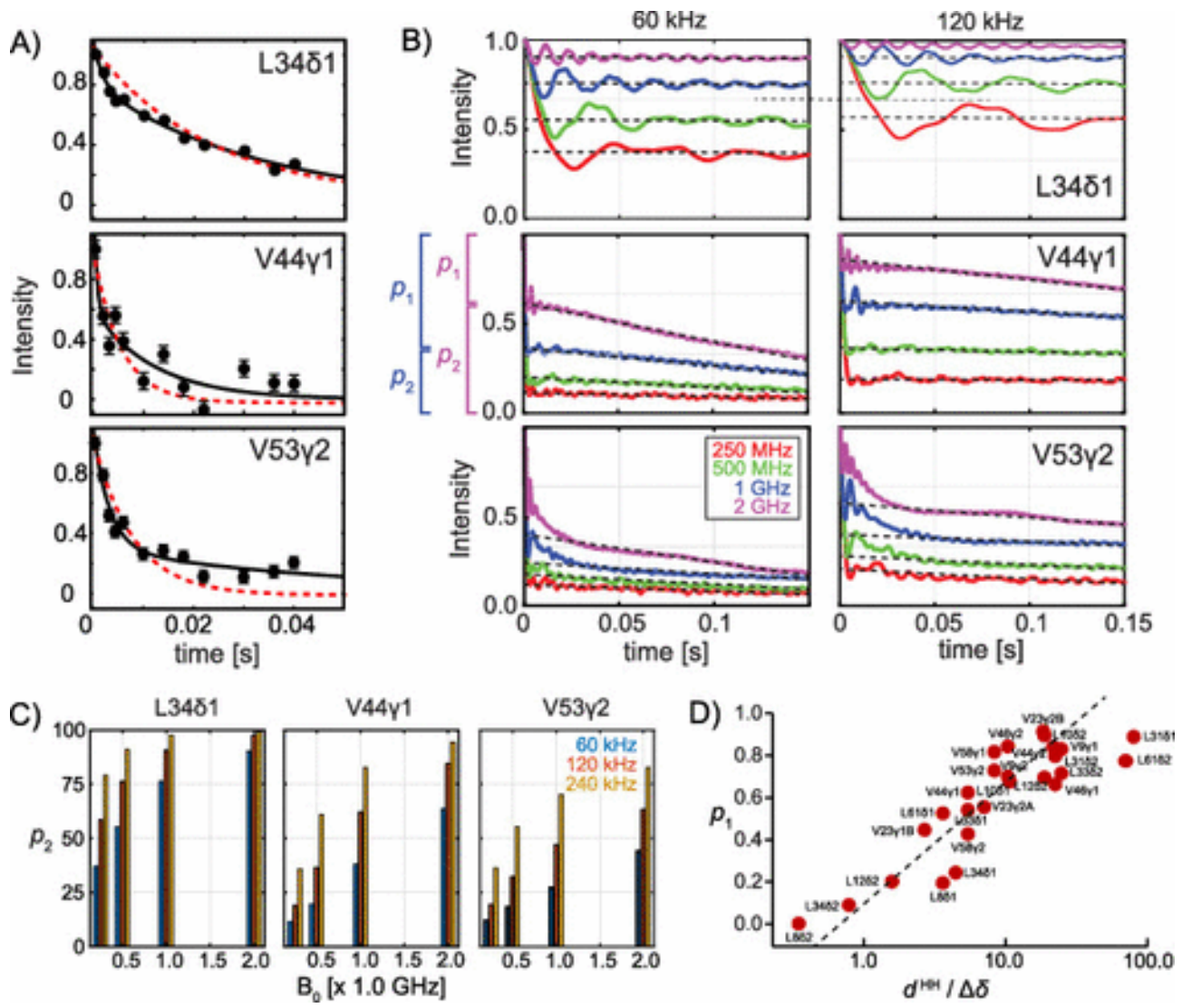

Sensitivity and resolution together determine the quality of NMR spectra in biological solids. Higher magic angle spinning frequencies yield a more efficient suppression of the coupling network and enable atomic-level investigations of protonated protein samples. On the other hand, truncation effects induced by higher magnetic fields have an impact on the achievable sensitivity and resolution. In this work, we address the question of how the proton dipolar coupling network affects the magnetic field strength-dependent gains in sensitivity and resolution. We find that-beyond the canonical $B_{0}{ }^{3 / 2}$ dependence-an additional factor of 2 in sensitivity can be achieved for residues embedded in the core of the protein, when the static magnetic field induces a transition from the strong- to the weak-coupling limit. The experiments are carried out using a selectively methylprotonated $\left({ }^{13} \mathrm{CH} 3\right) \alpha$-spectrin $\mathrm{SH} 3$ sample, at magnetic field strengths of $11.75 \mathrm{~T}\left({ }^{1} \mathrm{H}\right.$ Larmor frequency of $500 \mathrm{MHz}$ ) and $23.5 \mathrm{~T}\left({ }^{1} \mathrm{H}\right.$ Larmor frequency of $\left.1 \mathrm{GHz}\right)$. 


\section{Introduction}

Structure determination of protonated proteins using proton-detected solid-state NMR experiments, acquired at high magnetic fields $(1 \mathrm{GHz})$ and fast $(100 \mathrm{kHz})$ magic angle spinning (MAS), was first demonstrated in 2016. (1)Since then, fast MAS has revolutionized biological solid-state NMR. (2-7) Fast sample spinning at the magic angle is a prerequisite for proton-detected highresolution solid-state NMR. (8) Faster sample spinning averages anisotropic interactions more efficiently, which results in better sensitivity in correlation spectra. (9) The effect of the MAS rotation frequency on the resolution of amide and methyl proton spectra has been studied recently. $(8,10-12)$ It has been shown that $T_{2}^{\prime}$ of amide protons increases proportionally with the inverse of the rotor period for most residues in a model protein. (13) As the effective dipole-dipole interaction experienced by methyl protons is much larger than that for any other type of protons in a protein, methyl protons yield the largest line widths, even though the intramethyl dipolar couplings are scaled because of the fast rotation of the methyl group. (14) For a selectively methylprotonated sample in an otherwise deuterated background, MAS frequencies above $300 \mathrm{kHz}$ are necessary to yield $80 \%$ of the maximum attainable signal intensity. (11) For MAS frequencies below $70 \mathrm{kHz},{ }^{13} \mathrm{CHD}_{2}$ methyl group labeling is necessary to obtain optimal spectral quality. Above an MAS frequency of $70 \mathrm{kHz},{ }^{13} \mathrm{CH}_{3}$ isotopomers $(4,15-17)$ yield the best sensitivity depending on the density of the proton spin system. (12)

The maximum achievable rotation frequency of an MAS rotor is limited by the speed of sound on the rotor surface. (18) Higher rotation frequencies can therefore only be obtained for ever smaller diameter rotors. Lower sample mass is thus traded for faster MAS rates. At first sight, this seems to come at the cost of sensitivity. A $0.7 \mathrm{~mm}$ MAS rotor that spins as fast as $110 \mathrm{kHz}$ accommodates effectively less than a milligram of the sample. (19) As the length of an MAS rotor scales approximately linearly with its diameter, the amount of sample in a fast spinning rotor decreases proportionally with $r$. (3)On the other hand, the quality factor of the coil and the efficiency of detection increase with smaller coil diameters proportional to $1 / r$. (20) The apparent coherence decay time $T_{2}^{\prime}$ and thus the signal intensity during proton detection increase with higher MAS frequencies. Longer $T_{2}^{\prime}$ times contribute to the overall intensity linearly with $1 / r$. $(8,13,21)$ Even though the Hartmann-Hahn matching conditions become more selective at high MAS rotation frequencies, $(22,23)^{1} \mathrm{H}-T_{2}^{\prime}$ and $T_{1 p}$ relaxation times increase at faster MAS frequencies which facilitate multidimensional solid-state NMR experiments with multiple magnetization transfer steps. (7) Assuming that polarization transfer contributes another factor proportional to $1 / r$ to the relative signal intensity, comparable sensitivities, for example, 1.3 and $0.7 \mathrm{~mm}$ samples, are expected. This, in fact, has been observed experimentally. (1) When the MAS frequency is large enough to efficiently average proton-proton dipolar couplings such that ${ }^{1} \mathrm{H}$ transversal relaxation times do not any longer increase linearly with the rotation frequency, the optimum gain in the signal to noise ratio (SNR) is reached. For selectively methyl-protonated protein samples, this break-even point occurs for MAS frequencies on the order of $300 \mathrm{kHz}$. (11) For protonated samples, presumably higher MAS rotation frequencies are needed.

Obviously, proton sensitivity is not influenced by the employed MAS frequency alone. The detection sensitivity depends on the external magnetic field strength and is proportional to $B_{0}{ }^{3 / 2 .}(20,24)$ The experimental gain depends on a number of parameters including the conductivity of the sample and hardware parameters such as probe design, preamplifier, and receiver electronics. It is therefore not the aim of the manuscript to quantify the absolute field-dependent gain in sensitivity. We rather focus on the site-specific sensitivity ratios which are determined by the local geometry of the sample and the chemical shift differences among the coupled methyl groups. Even larger gains in sensitivity and resolution are expected in case proton-proton dipolar interactions transition from a strong coupling into a weak coupling limit with increasing magnetic field strength. This transition should 
occur when the chemical shift difference between interacting protons exceeds the strength of the involved effective dipolar coupling. In this manuscript, we explore the field-dependent relative sitespecific gain in the sensitivity of proton-detected ${ }^{1} \mathrm{H},{ }^{13} \mathrm{C}$ correlation spectra obtained for selectively methyl protonated microcrystalline protein samples. We find that, in particular, methyl groups that are located in proton dense regions yield gains in sensitivity that exceed the expected factor of 2.83, in case experiments are recorded at $24.2 \mathrm{~T}(1 \mathrm{GHz})$ instead of $12.1 \mathrm{~T}(500 \mathrm{MHz})$. These additional gains can be as large as an additional factor of 2 and depend on the local spin density and the chemical shift between interacting protons.

\section{Results}

This study was motivated by the observation that ${ }^{1} \mathrm{H},{ }^{13} \mathrm{C}$ correlation spectra that were recorded using protonated microcrystalline proteins at an MAS frequency of $106 \mathrm{kHz}$ are significantly better resolved at $1 \mathrm{GHz}$ in comparison to $500 \mathrm{MHz}$ (Figure 1; (14)). This applies, in particular, to the methyl region of the spectra. At the same time, the $\mathrm{C} \alpha$ region seems less affected. We explained this difference previously by considering the significantly higher effective dipolar couplings experienced by methyl protons compared to C $\alpha$ bound protons. $(14,25)$ However, the significant difference in resolution of the methyl region at the two magnetic fields raised the question on the field dependence of the proton line width.
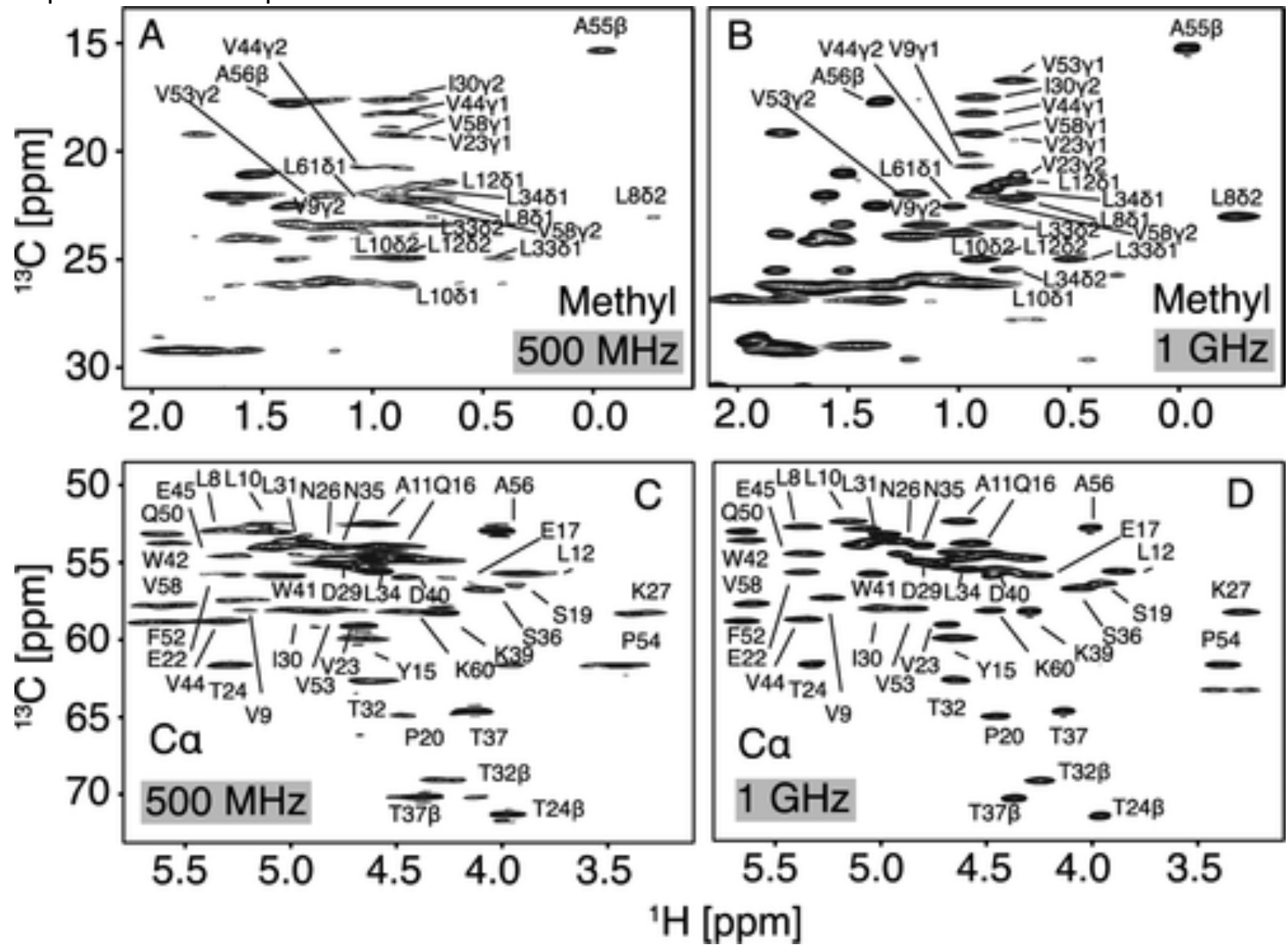

Figure $1 .{ }^{1} \mathrm{H},{ }^{13} \mathrm{C}$ correlation spectra of a fully protonated $\mathrm{u}-\left[{ }^{13} \mathrm{C},{ }^{15} \mathrm{~N}\right]$ microcrystalline $\alpha \mathrm{SH} 3$ domain recorded at an MAS frequency of $106 \mathrm{kHz}$ and at magnetic fields of $11.75 \mathrm{~T}(\mathrm{~A}, \mathrm{C})$ and $23.5 \mathrm{~T}(\mathrm{~B}, \mathrm{D})$, respectively. Methyl (top) and C $\alpha$ regions (bottom) of the spectra are shown. Representative 1D traces of spectra are shown in Figure S6. 
Figure $2 \mathrm{~A}$ shows ${ }^{1} \mathrm{H},{ }^{13} \mathrm{C}$ correlation spectra of a selectively ${ }^{13} \mathrm{CH}_{3}$ methyl-protonated $\mathrm{SH} 3$ sample recorded at $500 \mathrm{MHz}$ (left) and $1 \mathrm{GHz}$ (right). The spectra were acquired at an MAS frequency of 90 $\mathrm{kHz}$. The site-specific SNRs for each methyl group are represented in Figure $2 \mathrm{~B}$. The spectrum recorded at $1 \mathrm{GHz}$ shows a significantly higher SNR (on average, 2.1 times higher) for all methyl groups. To find out whether sensitivity improves beyond the theoretically expected factor, we calculated a theoretical SNR value for $1 \mathrm{GHz}$ from the experimental sensitivity at $500 \mathrm{MHz}$ using the following

equation

$\mathrm{SNR}_{1 \mathrm{GHz}}=\mathrm{SNR}_{500 \mathrm{MHz}} \times\left(\frac{\mathrm{LW}(\mathrm{C})_{500 \mathrm{MHz}} \times \mathrm{LW}(\mathrm{H})_{500 \mathrm{MHz}}}{\mathrm{LW}(\mathrm{C})_{1 \mathrm{GHz}} \times \mathrm{LW}(\mathrm{H})_{1 \mathrm{GHz}}}\right) \times\left(\frac{\epsilon_{1 \mathrm{GHz}}}{\epsilon_{500 \mathrm{MHz}}}\right) \times\left(\frac{1000}{500}\right)^{3 / 2}$

(1)where LW $(\chi)_{\psi}$ represents the line width of nucleus $\chi$ at a $B_{0}$ field of $\psi ; \varepsilon_{\psi}$ corresponds to the transfer efficiency after two $\mathrm{CP}$ steps in the ${ }^{1} \mathrm{H},{ }^{13} \mathrm{C}$ correlation experiments as $\varepsilon_{\psi}=\varepsilon(\mathrm{H} \rightarrow \mathrm{C}) \times \varepsilon(\mathrm{C} \rightarrow$ $\mathrm{H})$. As shown in Figure 2 $\mathrm{C}$, the site-specific $\mathrm{CP}$ efficiencies are slightly larger at $1 \mathrm{GHz}$ than at 500 $\mathrm{MHz} . \varepsilon_{\psi}$ is measured by comparing the cross-peak intensities of ${ }^{1} \mathrm{H},{ }^{13} \mathrm{C}$ correlation spectra that involve four versus two CP steps, (26) as described in Figure $\mathrm{S} 3$. The ${ }^{1} \mathrm{H}$ and ${ }^{13} \mathrm{C}$ line widths at $1 \mathrm{GHz}$ are slightly larger (mean: $68.9 \mathrm{~Hz}$ for ${ }^{1} \mathrm{H}$ and $21.4 \mathrm{~Hz}$ for ${ }^{13} \mathrm{C}$ ) compared to $500 \mathrm{MHz}$ (mean: $61.1 \mathrm{~Hz}$ for ${ }^{1} \mathrm{H}$ and $14.8 \mathrm{~Hz}$ for ${ }^{13} \mathrm{C}$ ), as seen from Figures $\underline{2} \mathrm{D}$ and $\underline{\mathrm{S}}$. Larger line widths at $1 \mathrm{GHz}$ can potentially be attributed to crystal heterogeneity, shimming, and the anisotropy of the bulk magnetic susceptibility (ABMS). Because of the increased magnetic fields, the SNR should improve $\sim 2.8$-fold $\left[=(1000 / 500)^{3 / 2}\right]$ theoretically.
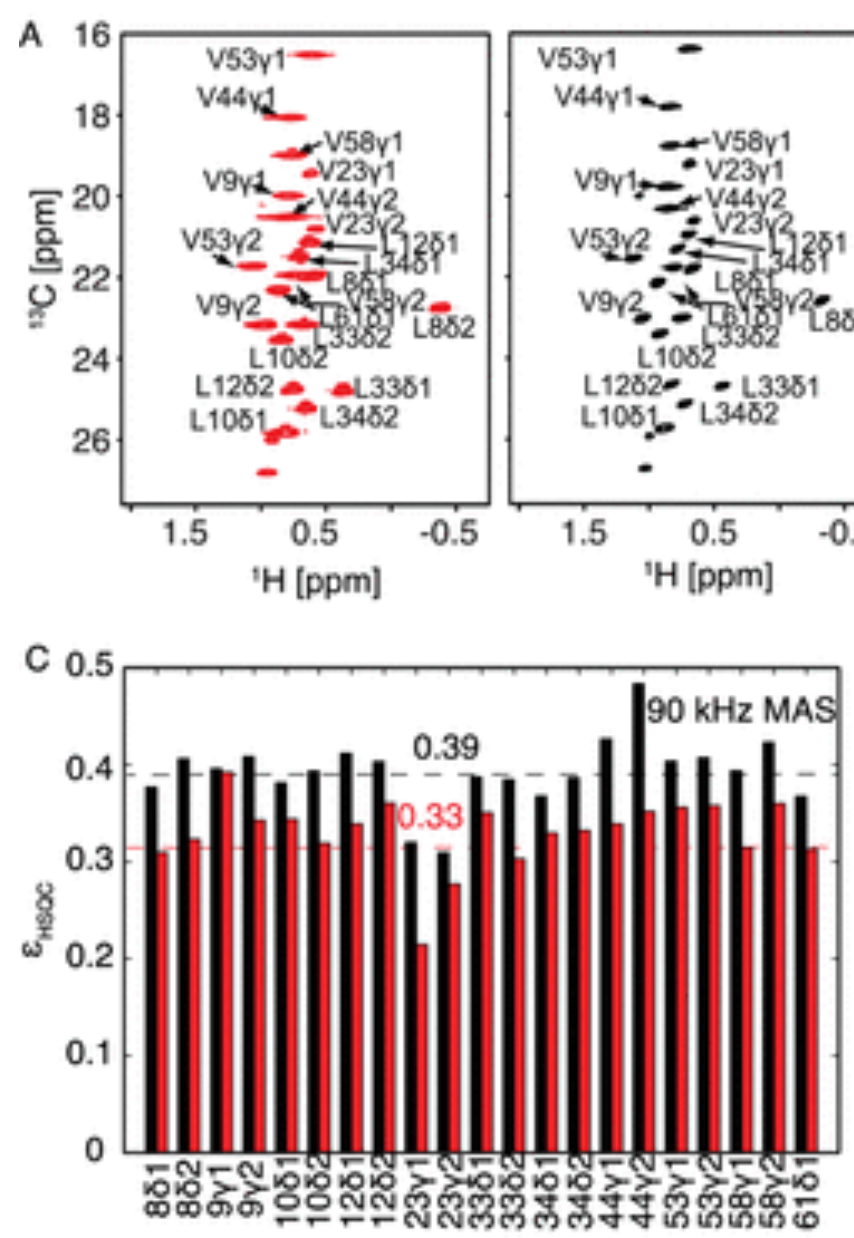

Residue
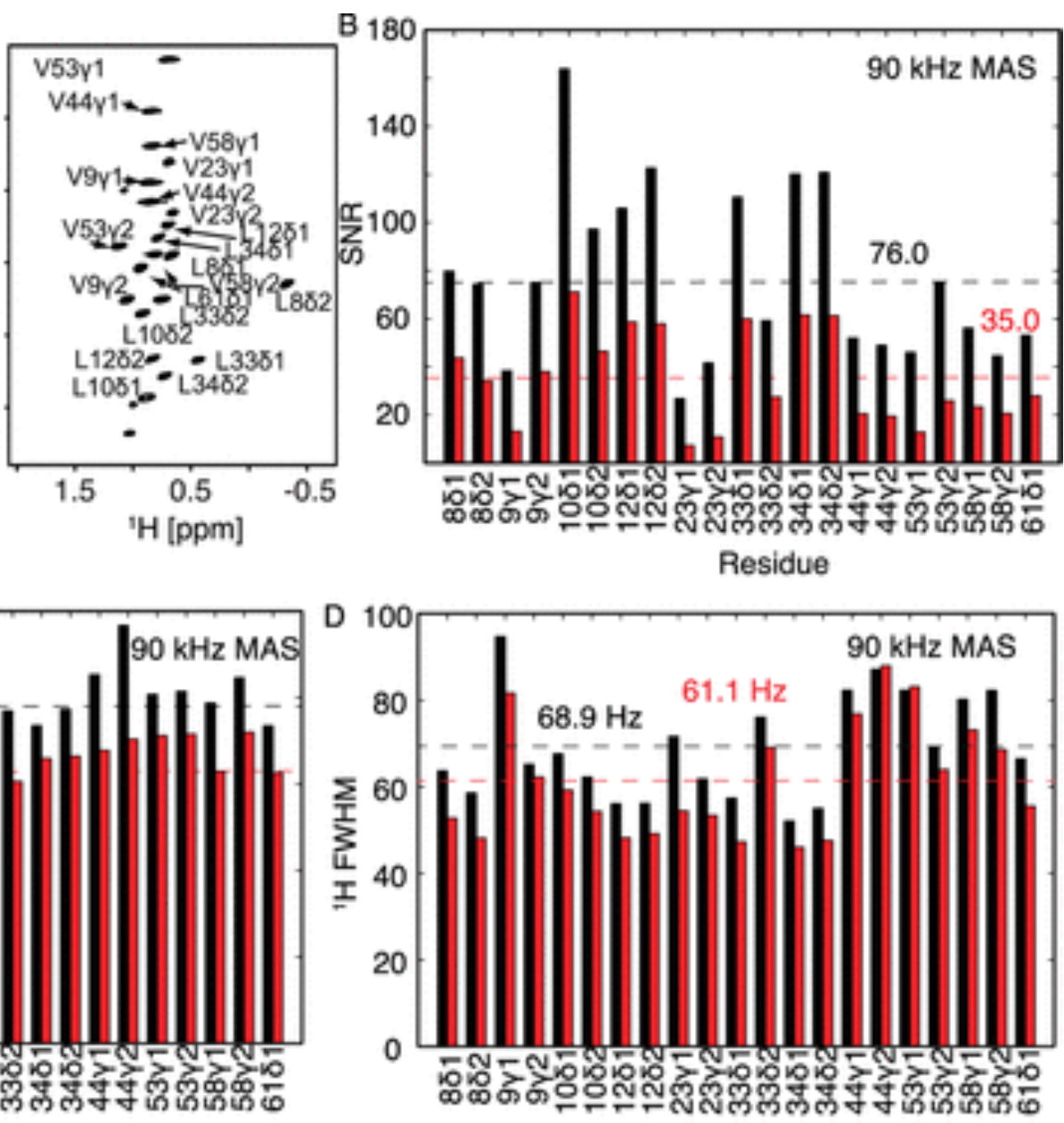

Residue 
Figure 2. (A) ${ }^{1} \mathrm{H},{ }^{13} \mathrm{C}$ correlation spectra recorded at an MAS frequency of $90 \mathrm{kHz}$ for a selectively valine and leucine methyl-protonated $\alpha \mathrm{SH} 3$ domain sample. Except for the methyl groups, the protein is fully deuterated, including the exchangeable sites. Measurements were performed at $B_{0}$ fields of $500 \mathrm{MHz}$ (red) and $1 \mathrm{GHz}$ (black). (B) SNR of the cross peaks increases from a mean of 35:1 to 76:1 when the field is increased from $500 \mathrm{MHz}$ to $1 \mathrm{GHz}$. (C) Site-specific polarization transfer efficiencies $\varepsilon_{\mathrm{HCH}}=\varepsilon(\mathrm{H} \rightarrow \mathrm{C}) \times \varepsilon(\mathrm{C} \rightarrow \mathrm{H})$ for Hartmann-Hahn-based cross polarization transfers at $500 \mathrm{MHz}$ and $1 \mathrm{GHz}$. The transfer efficiencies are slightly higher at $1 \mathrm{GHz}$ in comparison to 500 MHz. (D) Proton line width as a function of residue. The mean line width (fwhm) for spectra recorded at $1 \mathrm{GHz}$ is slightly larger compared to the line width obtained from spectra recorded at $500 \mathrm{MHz}$.

Figure $\underline{3} B$ shows the experimental site-specific SNR at $1 \mathrm{GHz}$ versus the SNR calculated from eq 1. Residues such as L33, L34 ( $\delta 1$ and $\delta 2), L 10$ ( $\delta 1$ and $\delta 2)$, and V44 ( $\gamma 1$ and $\gamma 2$ ) show a good agreement between experimental and predicted intensities as they are located close to the diagonal. For residues such as V9, V23, and V53 (inset to Figure $3 \mathrm{~B}$ ), the additional experimental gains can be as large as 2. To explain this unusual gain in the SNR at higher $B_{0}$ fields, we inspected the ${ }^{1} \mathrm{H}$ line shapes more carefully (Figure $\underline{3} \mathrm{~A}$ ). The ${ }^{1} \mathrm{H}$ resonances of most of the residues feature a broad and a narrow component. In the figure, the broad component is indicated with a red arrow. This is in agreement with the simulations that have predicted these spectral patterns previously (Xue et al., 2018, Figures $\underline{\mathrm{S} 3-\mathrm{S} 5}$ ). As the broad component is difficult to appreciate in Fourier transformed NMR spectra, we turned to the analysis of $T_{2}^{\prime}$ echo decays (Figure 4 ). We find experimentally that the apparent sitespecific ${ }^{1} \mathrm{H}$ transverse relaxation $\left(T_{2}^{\prime}\right)$ decays with a multiexponential behavior (Figure $\left.4 \mathrm{~A}\right)$. Fast methyl group rotation contributes an incoherent component to the ${ }^{1} \mathrm{H}-T_{2}^{\prime}$ decay. On the other hand, Simpson simulations that consider only coherent ${ }^{1} \mathrm{H},{ }^{1} \mathrm{H}$ dipolar interactions suggest that magnetization decays at least biexponentially, as described previously in ref (11). We therefore empirically describe the decay of ${ }^{1} \mathrm{H}$ transverse magnetization $\left(T_{2}^{\prime}\right)$ using the following equation

$$
S(t)=p_{0} \times \exp \left(-\frac{t}{T_{2}^{\text {inc }}}\right)+p_{1} \times \exp \left(-\frac{t}{T_{2}^{\text {coh, fast }}}\right)+p_{2} \times \exp \left(-\frac{t}{T_{2}^{\text {coh,slow }}}\right)
$$

with $p_{0}+p_{1}+p_{2}=1$

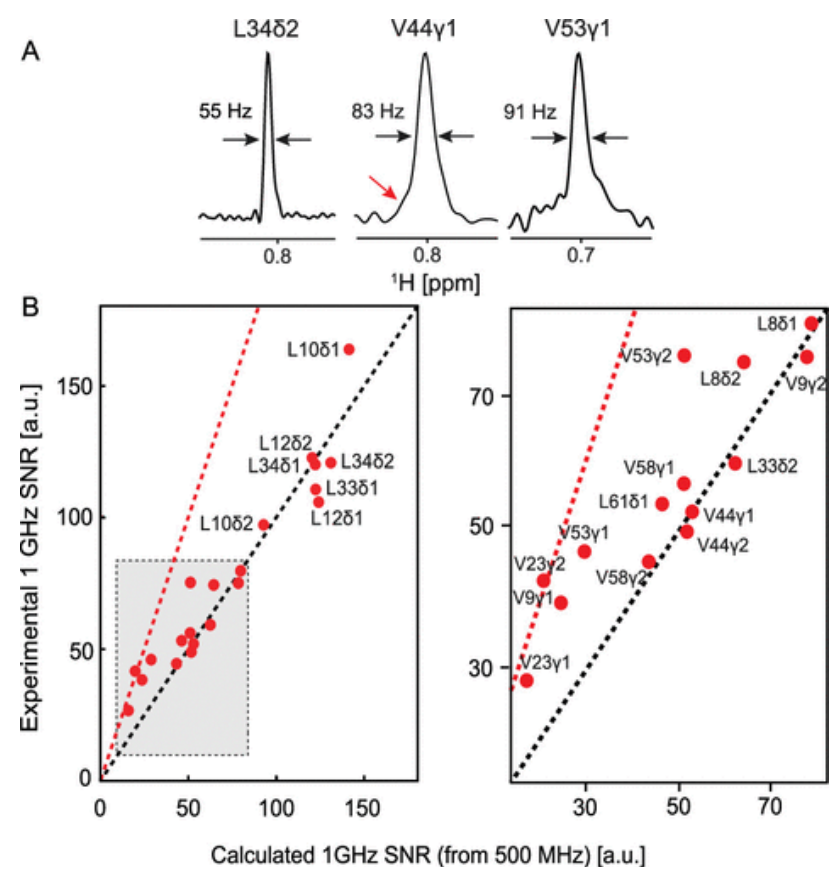

Figure 3. Traces extracted along the proton dimension of the ${ }^{1} \mathrm{H},{ }^{13} \mathrm{C}$ correlation spectrum from Figure $2 \mathrm{~A}(1 \mathrm{GHz})$ for the methyl cross peaks L3482, V44 $\gamma 1$, and V53 $\gamma 1$ for a selectively valine and leucine methyl-protonated $\alpha \mathrm{SH} 3$ domain sample. (B) Correlation of the experimental intensity at 
$1 \mathrm{GHz}$ (vertical axis) and the predicted intensity (horizontal axis) using intensity values obtained at $500 \mathrm{MHz}$ and eq 1. For peaks with relatively high intensity, a good correlation is observed (black, dashed line at $y=x$ ). For peaks with relatively low intensity, however, the experimental intensities at $1 \mathrm{GHz}$ are significantly higher than those expected from the $500 \mathrm{MHz}$ data (shaded region; magnified in the right-hand side panel, red, dashed line at $y=2 \times x$ ).
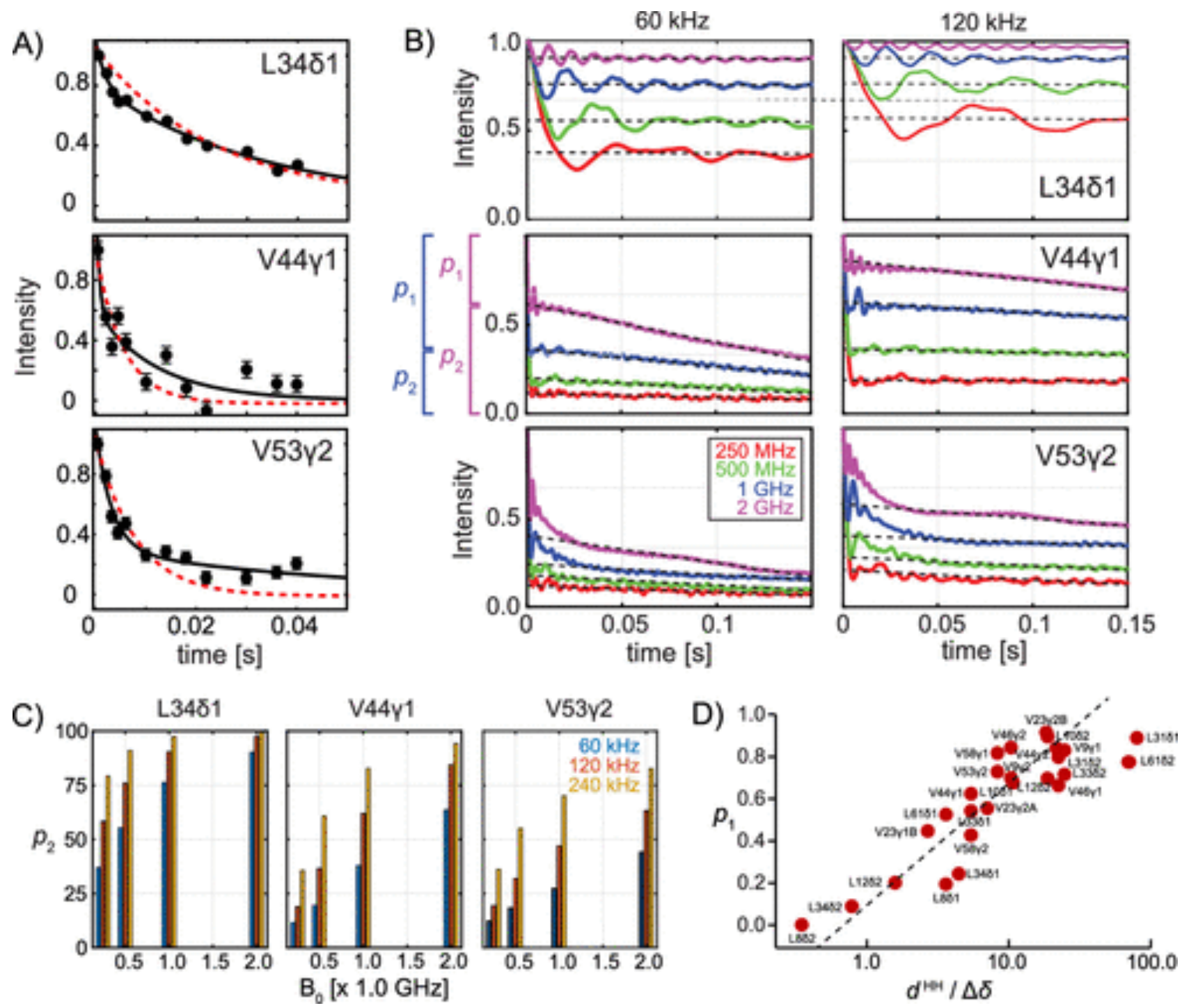

Figure 4. (A) Experimental ${ }^{1} \mathrm{H}-T_{2}^{\prime}$ decay curves (recorded by employing $90 \mathrm{kHz}$ MAS at a $B_{0}$ field of $1 \mathrm{GHz}$ ) for a few representative residues in the microcrystalline selectively $\mathrm{CH} 3$-protonated $\alpha \mathrm{SH} 3$ sample. Multiexponential fits are required to adequately describe the experimental data. (B) Simpson simulations of ${ }^{1} \mathrm{H}$ Hahn echo experiments for L $34 \delta 1$, V44 $\gamma 1$, and V53 $\gamma 2$, assuming exact geometry of the $\alpha \mathrm{SH} 3$ domain. For the simulations, nine proton spins have been taken into account. The parameters $p_{1}$ and $p_{2}$ are employed to empirically describe the simulations. (C) The slowly decaying component $p_{2}$ is shown as a function of $B_{0}$ and MAS frequency. (D) Correlation of $p_{1}$ and $d^{\mathrm{HH}} / \Delta \delta$ (ratio of proton-proton dipolar coupling to the chemical shift difference of the strongest coupling partner), assuming a magnetic field strength of $1 \mathrm{GHz}$.

In eq 2, the component proportional to $p_{0}$ refers to relaxation due to an incoherent mechanism with a characteristic time constant $T_{2}^{\text {inc }} . p_{1}$ and $p_{2}$ refer to the signal components that are due to coherent dephasing of magnetization and that decay with the characteristic time constants $T_{2}{ }^{\text {coh,fast }}$ and $T_{2}{ }^{\text {coh,slow, }}$, respectively.

To appreciate the multiexponential magnetization decay due to coherent effects, we performed Simpson simulations. $(27,28)$ In the simulation, a spin system involving nine spins is assumed using 
the PDB coordinate file of the $\alpha$-spectrin SH3 X-ray structure (PDB ID: 2NUZ). (29) Chemical shift data were taken from Asami et al. (30) The simulations were performed as functions of the $B_{0}$ field and for several MAS frequencies. Figure $4 \mathrm{~B}$ shows the simulated ${ }^{1} \mathrm{H}-T_{2}$ ' decay curves for $\mathrm{L} 34 \delta 1$, $\mathrm{V} 44 \mathrm{\gamma} 1$, and $\mathrm{V} 53 \mathrm{\gamma} 2$ at MAS rotation frequencies of 60 and $120 \mathrm{kHz}$ and for static magnetic fields of $250 \mathrm{MHz}, 500 \mathrm{MHz}, 1 \mathrm{G} \mathrm{Hz}$, and $2 \mathrm{GHz}$. All simulations show that magnetization declines much more slowly after an initial very fast decay. The associated intensity fractions are referred to as $p_{1}$ and $p_{2}$, respectively.

The $B_{0}$ dependence of the slowly decaying component $p_{2}$ is shown in Figure $4 \mathrm{C}$. Because of higher chemical shift dispersion, the contribution of the slowly decaying component to the spin echo signal increases when the static magnetic field $B_{0}$ is increased. For $V 53 \gamma 2, p_{2}$ increases from 0.19 to 0.64 while going from $250 \mathrm{MHz}$ to $2 \mathrm{GHz}$ at a fixed MAS frequency of $120 \mathrm{kHz}$. Faster MAS facilitates averaging of proton-proton dipolar interactions. As a consequence, an MAS frequency of $240 \mathrm{kHz}$ yields a $p_{2}$ value of 0.55 even at a static field of $500 \mathrm{MHz}$, while $p_{2}$ is as low as 0.27 at an MAS frequency of $60 \mathrm{kHz}$ at a static $B_{0}$ field of $1 \mathrm{GHz}$. L3482 is a methyl group that is only weakly coupled with other protons. As a consequence, $p_{2}$ reaches a value of 0.9 at an MAS frequency and $B_{0}$ field of $120 \mathrm{kHz}$ and $1 \mathrm{GHz}$, respectively.

In order to find out how the fast decaying component correlates with the effective proton-proton dipolar coupling and the chemical shift difference to the strongest coupling partner, defined as $d^{H H} / \Delta \delta$, we have represented $p_{1}$ as a function of $d^{H H} / \Delta \delta$ (Figure $4 \mathrm{D}$ ). In the simulation, a static magnetic field $B_{0}$ of $1 \mathrm{GHz}$ is assumed. $p_{1}$ correlates well with $d^{H+} / \Delta \delta$. For $d^{H+} / \Delta \delta<1$, we in fact find that the fast decaying component vanishes. As an example, $\mathrm{V} 53 \mathrm{\gamma} 2$ is densely packed in the core of $\alpha$-SH3. The nearest residue V58 1 exhibits a dipolar coupling of $d^{H H} / 2 \pi \sim 2392 \mathrm{~Hz}$, while $\Delta \delta \sim 288$ $\mathrm{Hz}$ at $1 \mathrm{GHz}$. The spin echo decay for $\mathrm{V} 53 \gamma 2$ yields a significantly higher $p_{1} \sim 0.7$ compared to $\mathrm{L} 34 \delta 2$, for which $d^{H+} / \Delta \delta$ is small $\left(p_{1} \sim 0.08 ; d^{H+} / 2 \pi \sim 237 \mathrm{~Hz}\right.$, while $\Delta \delta \sim 303 \mathrm{~Hz}$ at $\left.1 \mathrm{GHz}\right)$.

Figure $\underline{5}$ A shows the simulated signal intensities as a function of $B_{0}$ and the MAS frequency for a few representative residues. Obviously, higher intensities are obtained at higher magnetic field strengths. In order to appreciate how the intensity of a particular methyl group relates to the maximum possible sensitivity, we introduce the parameter $\mathrm{K}_{90 \mathrm{kHz}} . \mathrm{K}_{90 \mathrm{kHz}}$ refers to the fraction of the maximum achievable sensitivity (where simulated intensity reaches a plateau) obtained at an MAS frequency of $90 \mathrm{kHz}$. For $\mathrm{V} 53 \mathrm{\gamma} 2, \mathrm{~K}_{90 \mathrm{kHz}}$ amounts to $\sim 33 \%$ at $500 \mathrm{MHz}$, while this value increases to $\mathrm{K}_{90 \mathrm{kHz}} \sim 40 \%$ at a field of $1 \mathrm{GHz}$. Similarly, $\mathrm{K}_{90 \mathrm{kHz}}$ is equal to 87 and $93 \%$ for $\mathrm{L} 34 \delta 2$ at $B_{0}$ fields of 500 $\mathrm{MHz}$ and $1 \mathrm{GHz}$, respectively. On average, $\mathrm{K}_{90 \mathrm{kHz}}$ is on the order of $\sim 54 \%$ at a $B_{0}$ of $500 \mathrm{MHz}$, while $\mathrm{K}_{90 \mathrm{kHz}}$ increases to $\sim 61 \%$ at a $B_{0}$ field of $1 \mathrm{GHz}$ (Figure $\underline{5}$ ). This indicates that high magnetic fields imply gains in sensitivity that are beyond the canonical $B_{0}^{3 / 2}$ dependence. Figure $\underline{5} \mathrm{C}$ shows a correlation between the characteristic MAS frequency $\mathbf{V}^{(80)}{ }_{\text {MAS }}$ and the effective dipolar coupling $d^{\text {RSS }}$ for $\alpha$-SH3 (where $d^{\text {RSS is defined as }} d_{i}^{\text {RSS }}=\frac{\mu_{0}}{4 q} \gamma_{\mathrm{H}}^{2} \sqrt{\sum_{j}\left(\frac{1}{\left.r_{i j}\right)^{2}}\right)^{2}}$ ). The characteristic MAS frequency is defined as the frequency which is required to obtain $80 \%$ of the maximum intensity for a given residue. Again, higher magnetic fields facilitate MAS-induced averaging of proton dipolar couplings. $(11,12)$ 
A

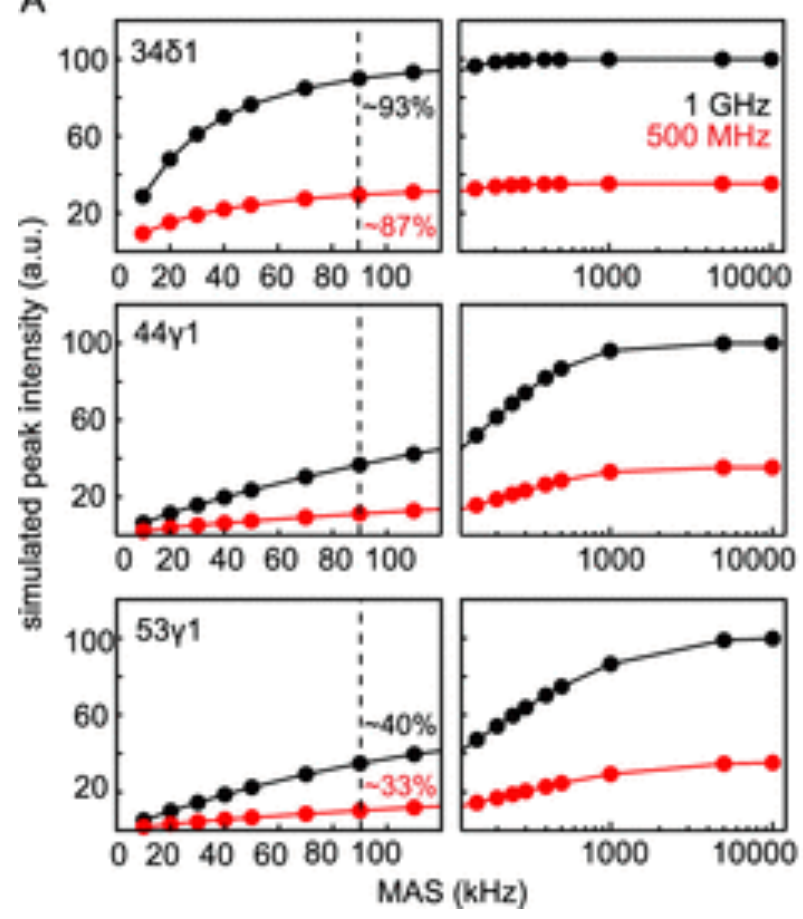

B

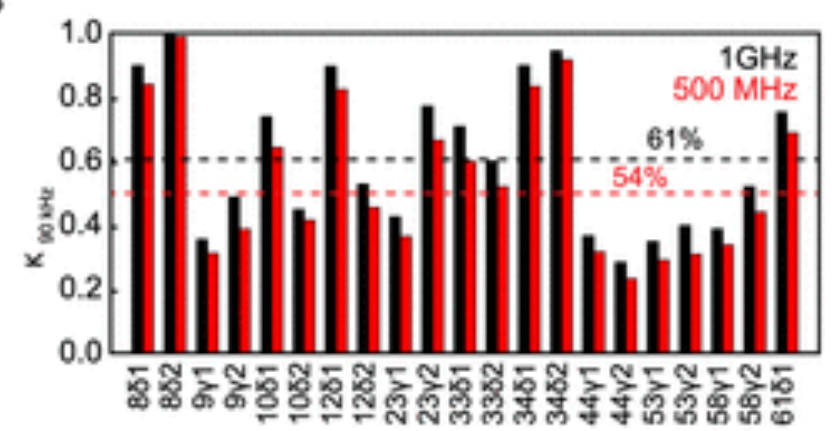

C

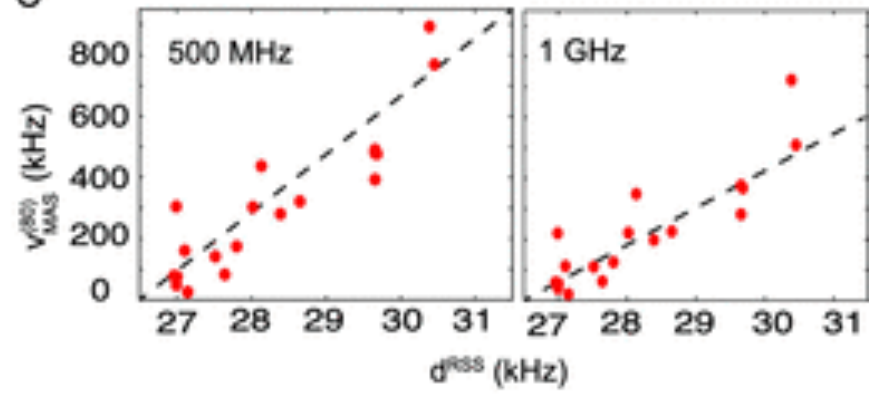

Figure 5. (A) Simulated intensities for methyl protons of L3482, V44 $\gamma 1$, and V53 $\gamma 1$ calculated by assuming $B_{0}$ fields of $500 \mathrm{MHz}$ and $1 \mathrm{GHz}$ and assuming that only valine and leucine methyl groups are labeled as ${ }^{13} \mathrm{CH}_{3}$ (while the rest of the protein is deuterated) for the $\alpha \mathrm{SH} 3$ domain sample. At an MAS frequency of $90 \mathrm{kHz}$, a systematically higher SNR is expected for $1 \mathrm{GHz}$ compared to 500 $\mathrm{MHz}$. The percent numbers in the figure $\left(\kappa_{90 \mathrm{kH} z}\right)$ indicate the fraction of the maximum achievable sensitivity for the particular B0 field at an MAS frequency of $90 \mathrm{kHz}$. (B) $\kappa_{90 \mathrm{kz} z}$ for each methyl group in $\alpha$-SH3 calculated for magnetic field strengths of $500 \mathrm{MHz}$ (red) and $1 \mathrm{GHz}$ (black). (C) Correlation of the characteristic MAS frequency necessary to obtain $80 \%$ of the maximum achievable intensity $v_{\mathrm{MAS}}{ }^{(80)}$ vs the effective dipolar coupling $d^{\mathrm{RSS}}$ at $500 \mathrm{MHz}$ (left) and $1 \mathrm{GHz}$ (right). The slope of the correlation plot decreases for higher fields, suggesting that high fields facilitate line narrowing by MAS.

\section{Conclusions}

In this work, we have compared the site-specific increase in sensitivity for methyl protons in a microcrystalline, selectively methyl-protonated $\alpha$-spectrin $\mathrm{SH} 3$ domain sample, implied by the increase in the external magnetic $B_{0}$ field from $500 \mathrm{MHz}$ to $1 \mathrm{GHz}$ by employing fast MAS (90 kHz). For residues that experience few proton-proton dipolar interactions, the increase in sensitivity closely matches the expected value of $\sim 2.1$, as described by eq 1 . However, the gain in SNR can be increased by an additional factor of $\sim 2$ for methyls that are embedded in a dense proton coupling network such as $\mathrm{V} 9 \gamma 1, \mathrm{~V} 23 \gamma 2$, and $\mathrm{V} 53 \gamma 1$. These additional gains can be explained by a decreased dipolar coupling to chemical shift difference ratio $\left(d^{H+H} / \Delta \delta\right)$, inducing a transition into the weak coupling limit. We find that the proton line shapes feature a broad and a narrow component. Using numerical simulations, we could show that the broad component contributes less at higher $B_{0}$ fields. Our results indicate that fast MAS in combination with high $B_{0}$ fields is essential to yield proton spectra with optimum sensitivity and resolution in the solid state. It is expected that modifying the proton network in the sample by protonation of the amide groups or the side chains may impact the site-specific intensity gains. (17) 


\title{
Materials and Methods
}

\author{
Sample Preparation
}

The microcrystalline, perdeuterated, and selectively methyl-protonated SH3 domain sample was prepared as described previously. (31) In brief, expression was carried out in a $100 \% \mathrm{D}_{2} \mathrm{O} \mathrm{M} 9$ medium, supplemented with ${ }^{15} \mathrm{~N}$-ammonium chloride and $\mathrm{u}-\left[{ }^{2} \mathrm{H},{ }^{13} \mathrm{C}\right]$-d-glucose. $\alpha$-Ketoisovalerate (2-keto-3-(methyl- $d_{3}$ )-butyric acid-4- ${ }^{13} \mathrm{C}$ sodium salt, Sigma-Aldrich) was added to the M9 medium 1 $\mathrm{h}$ prior to induction with $1 \mathrm{mM}$ IPTG (at $\mathrm{OD}_{600} 0.5-0.6$ ), yielding a $50 \%$ incorporation rate of $\mathrm{CH} 3$ isotopomers in either the pro-R or pro-S position of the valine and leucine side chains. Subsequent to overnight expression, the SH3 domain was purified via anion exchange and size exclusion chromatography. For crystallization, pure protein was lyophilized and dissolved in $100 \% \mathrm{D}_{2} \mathrm{O}$ (final concentration: $8-10 \mathrm{mg} / \mathrm{mL}$ ). Ammonium sulfate (dissolved in $100 \% \mathrm{D}_{2} \mathrm{O}$ ) was added to a final concentration of $100 \mathrm{mM}$, and the $\mathrm{pH}$ was adjusted to 8.0 by adding NaOD. The protonated sample was prepared by employing only protonated chemicals.

\section{Solid-State NMR}

NMR experiments were carried out at $B_{0}$ fields of $500 \mathrm{MHz}$ and $1 \mathrm{GHz}$ by employing a $0.7 \mathrm{~mm} \mathrm{H} / \mathrm{C} / \mathrm{N}$ triple-resonance MAS probe. As the sample was recrystallized from $100 \% D_{2} \mathrm{O}$, no solvent suppression was employed. For all experiments, the sample temperature was adjusted to the same effective value using DSS and the residual water signal for calibration. The pulse sequences used to quantify the transfer efficiency are reported in the Supporting Information (Figure S3). The following matching conditions were employed at a $B_{0}$ field of $1 \mathrm{GHz}: \omega_{1}\left({ }^{13} \mathrm{C}\right) / 2 \pi=60 \mathrm{kHz}$ and $\omega_{1}\left({ }^{1} \mathrm{H}\right) / 2 \pi=177 \mathrm{kHz}$ at an MAS frequency of $106 \mathrm{kHz}$ and $\omega_{1}\left({ }^{13} \mathrm{C}\right) / 2 \pi=60 \mathrm{kHz}$ and $\omega_{1}\left({ }^{1} \mathrm{H}\right) / 2 \pi=160$ $\mathrm{kHz}$ at an MAS frequency of $90 \mathrm{kHz}$. In all cases, a 90-100 ramped shape was used on the ${ }^{1} \mathrm{H}$ channel, whereas a constant amplitude pulse was used for ${ }^{13} \mathrm{C}$. For experiments carried out at $500 \mathrm{MHz}$, the following matching conditions were employed: $\omega_{1}\left({ }^{13} \mathrm{C}\right) / 2 \pi=40 \mathrm{kHz}$ and $\omega_{1}\left({ }^{1} \mathrm{H}\right) / 2 \pi=70 \mathrm{kHz}$ at an MAS frequency of $106 \mathrm{kHz}$ and $\omega_{1}\left({ }^{13} \mathrm{C}\right) / 2 \pi=40 \mathrm{kHz}$ and $\omega_{1}\left({ }^{1} \mathrm{H}\right) / 2 \pi=50 \mathrm{kHz}$ at an MAS frequency of $90 \mathrm{kHz}$. In all cases, a 70-100 ramped shape was used on the ${ }^{1} \mathrm{H}$ channel, whereas a constant amplitude pulse was used for ${ }^{13} \mathrm{C}$. The contact times for the transfers ${ }^{1 \mathrm{H}} \rightarrow{ }^{13} \mathrm{C}$ and ${ }^{13} \mathrm{C} \rightarrow{ }^{1 \mathrm{H}}$ were set to $500 \mu \mathrm{s}$ for both samples. The relaxation delay was set to 1 and $0.63 \mathrm{~s}$ in $1 \mathrm{GHz}$ and $500 \mathrm{MHz}$, respectively, which is about 1.5 times the experimentally determined bulk proton T1 (Figure S7). The error in signal intensities introduced by relaxation is estimated to be less than $10 \%$. The acquisition times were set to 20 and $70 \mathrm{~ms}$ in ${ }^{1} \mathrm{H}$ and ${ }^{13} \mathrm{C}$ dimensions, respectively. Proton line widths were compared to experiments recorded by employing an acquisition time of $50 \mathrm{~ms}$, which showed no gain in resolution. Signals were not apodized when line widths were compared. Of note, the same rotor was used for all the experiments in both the spectrometers.

\section{Numerical Simulations}

The numerical simulations were carried out using a nine-proton spin system, thus accounting for two neighboring methyl-containing side chains. Because the incorporation of ${ }^{13} \mathrm{CH}_{3}$ and ${ }^{12} \mathrm{CD}_{3}$ into the pro-R and pro-S positions occurs at random, selecting the two closest neighboring methyl groups for a given site overestimates the involved dipole-dipole couplings. Using the program SIMPSON, we have therefore calculated the methyl proton spectra for all permutations to reflect the actual isotope labeling of the sample. Subsequently, the average spectrum has been calculated. For the 
spin echo simulations, two closest methyl groups were chosen for a given methyl group; the gcompute method in the time domain was used with block diagonalization of Hamiltonians whenever possible. Long echo delays were simulated using a precalculated propagator of one rotor period which was raised to the exponent as necessary.

\section{Supporting Information}

The Supporting Information is available free of charge at https://pubs.acs.org/doi/10.1021/acs.jpcc.0c05407.

- Site specific intensities and proton line shapes, pulse sequences to record ${ }^{1} \mathrm{H},{ }^{13} \mathrm{C}$ spectra and Hartmann-Hahn CP efficiencies, experimental ${ }^{13} \mathrm{C}$ line widths, site-specific apparent ${ }^{1} \mathrm{H} T_{2}$ ' decay curves, $1 \mathrm{D}$ traces from correlation spectra, and bulk ${ }^{1} \mathrm{H} \mathrm{T}_{1}$ curves at 500 $\mathrm{MHz}$ and $1 \mathrm{GHz}(\underline{\mathrm{PDF}})$

\section{Author Information}

- Corresponding Authors

○ Riddhiman Sarkar-Helmholtz-Zentrum München (HMGU), Deutsches Forschungszentrum für Gesundheit und Umwelt, Ingolstädter Landstr. 1, 85764 Neuherberg, Germany; Munich Center for Integrated Protein Science (CIPS-M) at Department Chemie, Technische Universität München (TUM), Lichtenbergstr. 4, $85747 \quad$ Garching, Germany; http://orcid.org/0000-0001-90557897; Email: riddhiman.sarkar@helmholtz-muenchen.de

○ Bernd Reif - Helmholtz-Zentrum München (HMGU), Deutsches Forschungszentrum für Gesundheit und Umwelt, Ingolstädter Landstr. 1, 85764 Neuherberg, Germany; Munich Center for Integrated Protein Science (CIPS-M) at Department Chemie, Technische Universität München (TUM), Lichtenbergstr. 4, 85747 Garching, Germany; http://orcid.org/0000-0001-7368-7198; Email: reif@tum.de

\section{- Authors}

○ Kai Xue - Helmholtz-Zentrum München (HMGU), Deutsches Forschungszentrum für Gesundheit und Umwelt, Ingolstädter Landstr. 1, 85764 Neuherberg, Germany; Present Address: Max Planck Institute for Biophysical Chemistry, Department of NMR Based Structural Biology, Am Fassberg. 11, 37077 Goettingen, Germany

- Daniela Lalli - Centre de Résonance Magnétique Nucléaire a Très hauts Champs (FRE 2034-CNRS, Ecole Normale Supérieure de Lyon, Université Claude Bernard Lyon 1), Université de Lyon, 5 rue de la Doua, 69100 Villeurbanne, France; Present Address: Dipartimento di Scienze e Innovazione Tecnologica, Università del Piemonte Orientale Amedeo Avogadro, viale Teresa Michel, 15121 Alessandria, Italia

- Benita Koch-Munich Center for Integrated Protein Science (CIPS-M) at Department Chemie, Technische Universität München (TUM), Lichtenbergstr. 4, 85747 Garching, Germany

- Guido Pintacuda - Centre de Résonance Magnétique Nucléaire a Très hauts Champs (FRE 2034-CNRS, Ecole Normale Supérieure de Lyon, Université Claude Bernard Lyon 1), Université de Lyon, 5 rue de la Doua, 69100 Villeurbanne, France; http://orcid.org/0000-0001-7757-2144

$\circ$ Zdenek Tosner - Department of Chemistry, Faculty of Science, Charles University, Hlavova 8, 12842 Praha 2, Czech Republic 


\section{Notes}

The authors declare no competing financial interest.

\section{Acknowledgments}

This work was performed in the framework of the SFB-1035 (project B07; German Research Foundation, DFG). We acknowledge support from the Helmholtz-Gemeinschaft, the Deutsche Forschungsgemeinschaft (DFG, Grant Re1435), the Center for Integrated Protein Science Munich (CIPS-M), the CNRS (IR-RMN FR3050), the Czech Science Foundation (grant no. 20-00166J (Z.T.)), the European Research Council (ERC) (ERC-2014-CoG "P-MEM-NMR" GA n 648974), and the EU access project iNext (GA 653706). Computational resources were supplied by the project "e-Infrastruktura CZ" (e-INFRA LM2018140) provided within the program Projects of Large Research, Development and Innovations Infrastructures.

\section{References}

1. Andreas, L. B.; Jaudzems, K.; Stanek, J.; Lalli, D.; Bertarello, A.; Le Marchand, T.; Cala-De Paepe, D.; Kotelovica, S.; Akopjana, I.; Knott, B.Structure of fully protonated proteins by proton-detected magic-angle spinning NMR. Proc. Natl. Acad. Sci.

U.S.A. 2016, 113, 9187-9192, DOI: 10.1073/pnas.1602248113

2. Stanek, J.; Andreas, L. B.; Jaudzems, K.; Cala, D.; Lalli, D.; Bertarello, A.; Schubeis, T.; Akopjana, I.; Kotelovica, S.; Tars, K.NMR Spectroscopic Assignment of Backbone and Side-Chain Protons in Fully Protonated Proteins: Microcrystals, Sedimented Assemblies, and Amyloid Fibrils. Angew. Chem., Int. Ed. 2016, 55, 15503-15509, DOI: 10.1002/anie. 201607084

3. Vasa, S. K.; Singh, H.; Grohe, K.; Linser, R. Assessment of a Large Enzyme-Drug Complex by Proton-Detected Solid-State NMR Spectroscopy without Deuteration. Angew. Chem., Int. Ed.2019, 58, 5758-5762, DOI: 10.1002/anie.201811714

4. Gauto, D. F.; Estrozi, L. F.; Schwieters, C. D.; Effantin, G.; Macek, P.; Sounier, R.; Sivertsen, A. C.; Schmidt, E.; Kerfah, R.; Mas, G.Integrated NMR and cryo-EM atomicresolution structure determination of a half-megadalton enzyme complex. Nat. Commun. 2019, 10, 2697, DOI: 10.1038/s41467-019-10490-9

5. Gauto, D. F.; Macek, P.; Barducci, A.; Fraga, H.; Hessel, A.; Terauchi, T.; Gajan, D.; Miyanoiri, Y.; Boisbouvier, J.; Lichtenecker, R.Aromatic Ring Dynamics, Thermal Activation, and Transient Conformations of a 468 kDa Enzyme by Specific 1H-13C Labeling and Fast Magic-Angle Spinning NMR. J. Am. Chem.

Soc. 2019, 141, 11183-11195, DOI: 10.1021/jacs.9b04219

6. Kosol, S.; Gallo, A.; Griffiths, D.; Valentic, T. R.; Masschelein, J.; Jenner, M.; de los Santos, E. L. C.; Manzi, L.; Sydor, P. K.; Rea, D.Structural basis for chain release from the enacyloxin polyketide synthase. Nat. Chem. 2019, 11, 913-923, DOI: 10.1038/s41557019-0335-5

7. Orton, H. W.; Stanek, J.; Schubeis, T.; Foucaudeau, D.; Ollier, C.; Draney, A. W.; Le Marchand, T.; Cala-De Paepe, D.; Felli, I. C.; Pierattelli, R.Protein NMR Resonance 
Assignment without Spectral Analysis: 5D SOlid-State Automated Projection SpectroscopY (SO-APSY). Angew. Chem., Int. Ed. 2020, 59, 2380- 2384, DOI:

10.1002/anie.201912211

8. Samoson, A.; Tuherm, T.; Gan, Z. High-Field High-Speed MAS Resolution Enhancement in $1 \mathrm{H}$ NMR Spectroscopy of Solids. Solid State Nucl. Magn.

Reson. 2001, 20, 130-136, DOI: 10.1006/snmr.2001.0037

9. Böckmann, A.; Ernst, M.; Meier, B. H. Spinning proteins, the faster, the better?. J. Magn. Reson. 2015, 253, 71-79, DOI: 10.1016/j.jmr.2015.01.012

10. Malär, A. A.; Smith-Penzel, S.; Camenisch, G.-M.; Wiegand, T.; Samoson, A.; Böckmann, A.; Ernst, M.; Meier, B. H. Quantifying proton NMR coherent linewidth in proteins under fast MAS conditions: a second moment approach. Phys. Chem. Chem.

Phys. 2019, 21, 18850-18865, DOI: 10.1039/c9cp03414e

11. Xue, K.; Sarkar, R.; Motz, C.; Asami, S.; Decker, V.; Wegner, S.; Tosner, Z.; Reif, B. Magic-Angle Spinning Frequencies beyond 300 kHz Are Necessary To Yield Maximum Sensitivity in Selectively Methyl Protonated Protein Samples in Solid-State NMR. J. Phys. Chem. C 2018, 122, 16437-16442, DOI: 10.1021/acs.jpcc.8b05600

12. Xue, K.; Sarkar, R.; Tosner, Z.; Lalli, D.; Motz, C.; Koch, B.; Pintacuda, G.; Reif, B. MAS dependent sensitivity of different isotopomers in selectively methyl protonated protein samples in solid state NMR. J. Biomol. NMR 2019, 73, 625-631, DOI: 10.1007/s10858019-00274-0

13. Penzel, S.; Oss, A.; Org, M.-L.; Samoson, A.; Böckmann, A.; Ernst, M.; Meier, B. H. Spinning faster: protein NMR at MAS frequencies up to $126 \mathrm{kHz}$. J. Biomol. NMR 2019, 73, 19-29, DOI: 10.1007/s10858-018-0219-9

14. Xue, K.; Sarkar, R.; Motz, C.; Asami, S.; Camargo, D. C. R.; Decker, V.; Wegner, S.; Tosner, Z.; Reif, B. Limits of Resolution and Sensitivity of Proton Detected MAS SolidState NMR Experiments at $111 \mathrm{kHz}$ in Deuterated and Protonated Proteins. Sci. Rep. 2017, 7, 7444, DOI: 10.1038/s41598-017-07253-1

15. Linser, R.; Bardiaux, B.; Andreas, L. B.; Hyberts, S. G.; Morris, V. K.; Pintacuda, G.; Sunde, M.; Kwan, A. H.; Wagner, G. Solid-State NMR Structure Determination from Diagonal-Compensated, Sparsely Nonuniform-Sampled 4D Proton-Proton Restraints. $J$. Am. Chem. Soc. 2014, 136, 11002-11010, DOI: 10.1021/ja504603g

16. Vasa, S. K.; Rovó, P.; Linser, R. Protons as Versatile Reporters in Solid-State NMR Spectroscopy. Acc. Chem. Res. 2018, 51, 1386-1395, DOI: 10.1021/acs.accounts.8b00055

17. Kurauskas, V.; Crublet, E.; Macek, P.; Kerfah, R.; Gauto, D. F.; Boisbouvier, J.; Schanda, P.Sensitive proton-detected solid-state NMR spectroscopy of large proteins with selective CH3 labelling: application to the 50S ribosome subunit. Chem.

Commun. 2016, 52, 9558-9561, DOI: 10.1039/c6cc04484k 
18. Chen, P.; Albert, B. J.; Gao, C.; Alaniva, N.; Price, L. E.; Scott, F. J.; Saliba, E. P.; Sesti, E. L.; Judge, P. T.; Fisher, E. W.; Barnes, A. B. Magic angle spinning spheres. Sci.

$A d v$. 2018, 4, eaau1540 DOI: $10.1126 /$ sciadv.aau 1540

19. Agarwal, V.; Penzel, S.; Szekely, K.; Cadalbert, R.; Testori, E.; Oss, A.; Past, J.; Samoson, A.; Ernst, M.; Böckmann, A.; Meier, B. H. De Novo 3D Structure Determination from Submilligram Protein Samples by Solid-State $100 \mathrm{kHz}$ MAS NMR Spectroscopy. Angew.

Chem., Int. Ed. 2014, 53, 12253-12256, DOI: 10.1002/anie.201405730

20. Hoult, D. I.; Richards, R. E. The signal-to-noise ratio of the nuclear magnetic resonance experiment. J. Magn. Reson. 2011, 213, 329-343, DOI: 10.1016/j.jmr.2011.09.018

21. Reif, B.; Griffin, R. G. $1 \mathrm{H}$ detected $1 \mathrm{H}, 15 \mathrm{~N}$ correlation spectroscopy in rotating solids. $J$. Magn. Reson. 2003, 160, 78-83, DOI: 10.1016/s1090-7807(02)00035-6

22. Samoson, A. H-MAS. J. Magn. Reson. 2019, 306, 167-172, DOI: 10.1016/j.jmr.2019.07.010

23. Tošner, Z.; Sarkar, R.; Becker-Baldus, J.; Glaubitz, C.; Wegner, S.; Engelke, F.; Glaser, SJ; Reif, B. Overcoming Volume Selectivity of Dipolar Recoupling in Biological SolidState NMR Spectroscopy. Angew. Chem., Int. Ed. 2018, 57, 14514-14518, DOI: 10.1002/anie. 201805002

24. Hoult, D. I. The NMR receiver: A description and analysis of design. Prog. Nucl. Magn. Reson. Spectrosc. 1978, 12, 41-77, DOI: 10.1016/0079-6565(78)80002-8

25. Zorin, V. E.; Brown, S. P.; Hodgkinson, P. Origins of linewidth in $1 \mathrm{H}$ magic-angle spinning NMR. J. Chem. Phys. 2006, 125, 144508, DOI: 10.1063/1.2357602

26. Penzel, S.; Smith, A. A.; Agarwal, V.; Hunkeler, A.; Org, M.-L.; Samoson, A.; Böckmann, A.; Ernst, M.; Meier, B. H. Protein resonance assignment at MAS frequencies approaching $100 \mathrm{kHz}$ : a quantitative comparison of J-coupling and dipolar-coupling-based transfer methods. J. Biomol. NMR 2015, 63, 165- 186, DOI: 10.1007/s10858-015-9975-y

27. Bak, M.; Rasmussen, J. T.; Nielsen, N. C. SIMPSON: A General Simulation Program for Solid-State NMR Spectroscopy. J. Magn. Reson. 2000, 147, 296-330, DOI: 10.1006/jmre.2000.2179

28. Tošner, Z.; Andersen, R.; Stevensson, B.; Edén, M.; Nielsen, N. C.; Vosegaard, T. Computer-intensive simulation of solid-state NMR experiments using SIMPSON. $J$. Magn. Reson. 2014, 246, 79-93, DOI: 10.1016/j.jmr.2014.07.002

29. Chevelkov, V.; Faelber, K.; Schrey, A.; Rehbein, K.; Diehl, A.; Reif, B. Differential Line Broadening in MAS solid-state NMR due to Dynamic Interference. J. Am. Chem. Soc. 2007, 129, 10195- 10200, DOI: 10.1021/ja072024c

30. Asami, S. Method Development for Biomolecular Solid-State NMR Spectroscopy; Humboldt-Universität zu Berlin, Mathematisch-Naturwissenschaftliche Fakultät I, 2014. 
31. Agarwal, V.; Xue, Y.; Reif, B.; Skrynnikov, N. R. Protein side-chain dynamics as observed by solution- and solid-state NMR: a similarity revealed. J. Am. Chem.

Soc. 2008, 130, 16611-16621, DOI: 10.1021/ja804275p 